Original Article

\title{
Echocardiographic and electrocardiographic parameters during the normal postpartum period in toy breeds of dogs
}

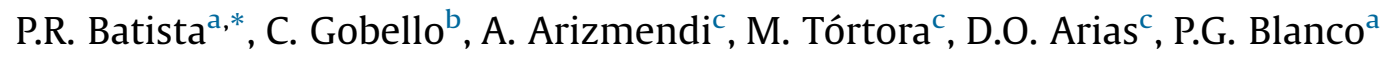 \\ a Cardiology Service and Laboratory of Reproductive Physiology (LAFIRE), Faculty of Veterinary Sciences, National University of La Plata, La Plata, Argentina \\ ${ }^{\mathrm{b}}$ Laboratory of Reproductive Physiology (LAFIRE), Faculty of Veterinary Sciences, National University of La Plata, La Plata, Argentina \\ ${ }^{\mathrm{c}}$ Cardiology Service, Faculty of Veterinary Sciences, National University of La Plata, La Plata, Argentina
}

\section{A R T I C L E I N F O}

Article history:

Accepted 17 October 2017

\section{Keywords:}

Canine

Puerperium

Echocardiography

Electrocardiography

Blood pressure

\begin{abstract}
A B S T R A C T
The aim of this study was to evaluate echocardiographic and electrocardiographic parameters during the normal canine postpartum period. Twenty clinically healthy pregnant bitches of toy breeds (11 Miniature poodles, five Yorkshire terriers, two Maltese terriers and two Bichons Frises) were evaluated on days -3 , $3,10,17,24,38,52$ and 80 relative to parturition (day 0 ). During the first postpartum week, the width of the interventricular septum in systole, the shortening fraction and the left atrium size decreased, while the left ventricle internal diameter in systole and end systolic stress increased. There were progressive decreases in the velocity of circumferential fibre shortening, stroke volume, cardiac output, and mitral $\mathrm{E}$ and A wave values. Systolic blood pressure increased markedly during the first postpartum week to gradually increase thereafter. Heart rate and corrected QT interval progressively decreased, while P wave amplitude increased. QRS complex amplitude decreased in the second week after parturition and then increased during the following weeks. In conclusion, there were changes in systolic function and some structural adaptive changes in the bitch during the first 80 days postpartum. In addition, maternal heart rate and corrected QT interval decreased, while P wave and QRS amplitudes increased.
\end{abstract}

(c) 2017 Elsevier Ltd. All rights reserved.

\section{Introduction}

Canine pregnancy is characterised by important adaptive changes, many of which occur in the cardiovascular system. These changes include an increase in total blood volume and cardiac output, associated with eccentric myocardial hypertrophy, and a decrease in peripheral vascular resistance (Abbott, 2010; Blanco et al., 2011). There is a decrease in the $P$ wave amplitude, an increase in the amplitude and duration of the QRS complex, and an increase in ventricular repolarisation time (Blanco et al., 2012).

The progression of some of these adaptive changes after parturition has been studied in human beings (Zatuchni, 1951; Robson et al., 1987), cattle (Neubert and Schäfer, 1977; Zarifi et al., 2012), goats (Olsson et al., 2001) and rodents (Wong et al., 2002; Poole et al., 2014). The postpartum period is characterised by reversal of most of the structural, functional and electrophysiological cardiac changes that occurred during pregnancy. Lactation also imposes a considerable strain on the cardiovascular system,

\footnotetext{
* Corresponding author.

E-mail address: pbatista@fcv.unlp.edu.ar (P.R. Batista).
}

associated with a high metabolic demand (Mezzacappa et al., 2001).

In view of the structural, functional and electrical cardiac physiological adaptive changes during canine pregnancy and lactation, it is of interest to describe their normal pattern of changes after parturition so that postpartum cardiovascular abnormalities could be detected and treated early. Whilst changes in heart rate postpartum and during lactation have been reported in bitches (Olsson et al., 2003a; Abbott, 2010), other cardiac changes after parturition have not been described. The aim of the present study was to evaluate the echocardiographic and electrocardiographic changes during the normal canine postpartum period.

\section{Materials and methods}

Animals

The study included 20 clinically healthy, pedigree, small breed pregnant bitches (11 Miniature poodles, five Yorkshire terriers, two Maltese terriers and two Bichons Frises), aged 1-5 years (mean \pm standard deviation, SD, $3.55 \pm 0.16$ years) and weighing $1.5-6.0 \mathrm{~kg}$ (mean $\pm \mathrm{SD} 3.6 \pm 0.3 \mathrm{~kg}$ at postpartum day 80). After ultrasonographic confirmation of pregnancy (day -3; England et al., 2003), bitches 
were evaluated on days $-3,3,10,17,24,38,52$ and 80 after parturition (Batista et al., 2013); day 0 was defined as the day of parturition. All bitches whelped healthy puppies at term. The weaning date was $60 \pm 2$ days after parturition. The study was approved by the Faculty Institutional Care and Animal Use Committee (approval number 42.3.14P; date of approval 26 August 2014).

\section{Echocardiographic evaluation}

Echocardiographic evaluations were carried out with the animals in a standing position using a $7-10 \mathrm{MHz}$ transducer (Toshiba Nemio XG; Chetboul et al., 2005). No sedation was required. To minimise variability, three consecutive measurements of each parameter were acquired and measured by a single trained operator (Thomas et al., 1993; Gottdiener et al., 2004; Nagueh et al., 2009). In case of marked sinus arrhythmia, six measurements of heart rate (HR) were performed.

Interventricular septum thickness in diastole (IVSd, $\mathrm{mm}$ ) and systole (IVSs, $\mathrm{mm}$ ), left ventricle internal diameter in diastole (LVDd, $\mathrm{mm}$ ) and systole (LVDs, $\mathrm{mm}$ ), and left ventricular free wall thickness in diastole (LVFWd, $\mathrm{mm}$ ) and systole (LVFWs, $\mathrm{mm}$ ), were measured in the right parasternal short axis view in M mode (Kienle, 1998). In the right parasternal long axis view, left atrial size (LA, mm) was measured from cranial to caudal along a line parallel to the mitral annulus that bisects the atrium (Boon, 1998; Rishniw and Erb, 2000).

As a measure of systolic function, shortening fraction (SF, \%) was calculated as (LVDd - LVDs)/LVDd $\times 100$ (Kienle, 1998). Velocity of circumferential fibre shortening (Vcf, circumferences/s), end systolic stress (ESS, dynes $/ \mathrm{cm}^{2}$ ) and relative wall thickness index (RWT) were calculated according to Kienle (1998), Boon (1998) and Vuille and Weyman (1994). The velocity time integral (VTI) was determined from the pulsed wave aortic spectrogram at the site of the apical transducer. Stroke volume (SV) was calculated as the product of the velocity time integral (VTI) and the cross-sectional area of the aorta (Boon, 1998). Mitral E wave (E) and A wave (A) peak velocity $(\mathrm{m} / \mathrm{s})$, deceleration time $(\mathrm{Dt})$ of $\mathrm{E}$ wave $(\mathrm{ms})$ and $\mathrm{E} / \mathrm{A}$ ratio $(\mathrm{E} / \mathrm{A})$ were determined by pulsed wave Doppler measurements in the apical four chamber view.

Systolic blood pressure $(\mathrm{mm} \mathrm{Hg}$ ) was determined with bitches in lateral recumbency. Measurements were carried out using a Doppler flow detector (DV610 Medmega; Brown et al., 2007). Each evaluation was performed under identical conditions, using the same location, after acclimatisation for $10 \mathrm{~min}$, and three consecutive measurements were recorded from the same location and position.

\section{Electrocardiographic evaluations}

A 10-lead electrocardiogram (ECG) was obtained in unsedated dogs positioned in right lateral recumbency. The animals were gently restrained with the forelimbs held perpendicular with the body and slightly separated (Ferasin et al., 2010). All electrocardiographic examinations were performed between 9.00 and $11.00 \mathrm{am}$ under the same environmental conditions (Olsson et al., 2003a).

Tracings were recorded from leads I-III, aVR, aVL, aVF, CV6LU, CV6LL, CV5RL and V10 at paper speeds of 25 and $50 \mathrm{~mm} / \mathrm{s}$ with a gain of $10 \mathrm{~mm} / \mathrm{mV}$. Each ECG was analysed by a single trained operator. Heart rate (beats per min, bpm) and cardiac rhythm (normal sinus rhythm or sinus arrhythmia) were assessed at a paper speed of $25 \mathrm{~mm} / \mathrm{s}$. In lead II, mean electrical axis (MEA, degrees). P wave amplitude (mV) and duration (ms), PR interval (ms), QRS complex amplitude (mV) and duration (ms), QT interval (ms) and ST segment amplitude (mV) were calculated manually at a paper speed of $50 \mathrm{~mm} / \mathrm{s}$ (Tilley, 1992). The mean of each parameter was calculated on the basis of the three measured beats in case of sinus rhythm or six measured beats in case of marked sinus arrhythmia (Blanco et al., 2012). The RR interval immediately preceding each complex was recorded and QT interval was corrected (QTc) using the formula QTc= QT-0.087(RR-1000) (Tattersall et al., 2006).

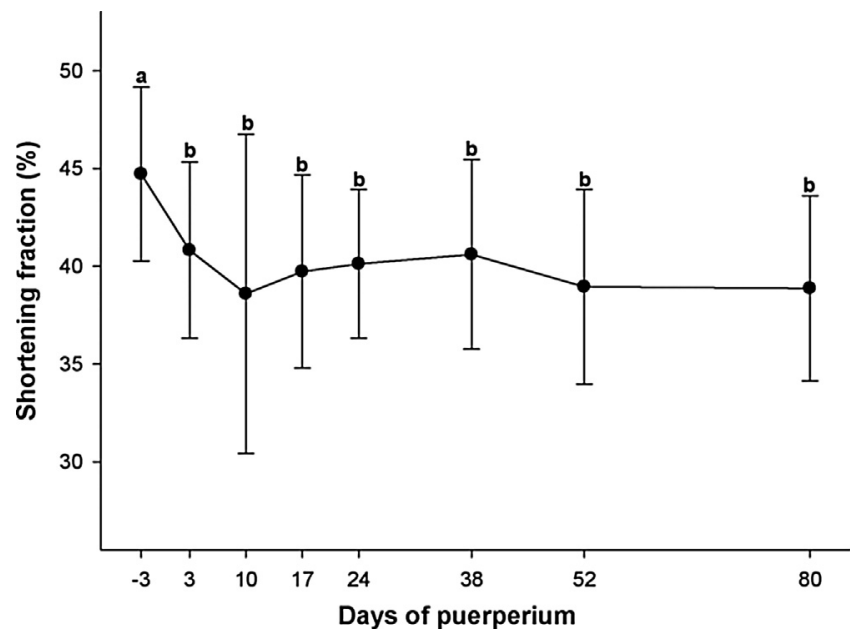

Fig. 1. Shortening fraction (SF; mean \pm standard deviation). Different letters indicate significant differences $(P<0.05)$ among days.

\section{Statistical analysis}

Data were analysed using SPSS 19.0 (IBM). Normality of distribution was determined using the Shapiro-Wilk test. Variables were analysed by repeated measures analysis of variance (ANOVA), followed by Tukey's test. Cardiac rhythm was assessed using the $\chi^{2}$ test. $P<0.05$ was considered to be significant.

\section{Results}

\section{Echocardiographic and systolic blood pressure}

During the first postpartum week, IVSs $(P<0.01$; Table 1$)$, SF $(P<0.01$; Fig. 1$)$, and LA $(P<0.01$; Table 1$)$ decreased, while LVDs $(P<0.01$; Table 1$)$ and ESS $(P<0.01$; Fig. 2$)$ increased. $\operatorname{Vcf}(P<0.01$; Table 1$)$, SV $(P<0.01$; Fig. 3$), \mathrm{CO}(P<0.01$; Fig. 4$), \mathrm{E}(P<0.05)$ and $\mathrm{A}$ $(P<0.05$; Fig. 5$)$ progressively decreased during the postpartum period. Systolic blood pressure increased most during the first week, followed by a gradual increase through the end of the study $(P<0.01$; Fig. 6). However, IVSd, LVDd, LVFWd, LVFWs, RWT, DT and $\mathrm{A} / \mathrm{E}$ remained unchanged throughout the study $(P>0.05$; Table 1).

\section{Electrocardiographic evaluations}

Heart rate $(P<0.01$; Fig. 7$)$ and QTc $(P<0.01)$ progressively decreased during the postpartum period, while $P$ wave amplitude increased $(P<0.01$; Table 2). QRS amplitude decreased in the second week after parturition and then increased during the

Table 1

Echocardiographic parameters (mean \pm standard deviation) of 20 bitches of toy breeds evaluated from day -3 to day 80 postpartum (day 0 is the day of parturition).

\begin{tabular}{|c|c|c|c|c|c|c|c|c|}
\hline & \multicolumn{8}{|c|}{ Postpartum days } \\
\hline & -3 & 3 & 10 & 17 & 24 & 38 & 52 & 80 \\
\hline IVSd (mm) & $5.5 \pm 0.5$ & $5.6 \pm 0.7$ & $5.5 \pm 0.5$ & $5.5 \pm 0.6$ & $5.5 \pm 0.7$ & $5.5 \pm 0.5$ & $5.3 \pm 0.6$ & $5.4 \pm 0.6$ \\
\hline LVDd (mm) & $21.5 \pm 2$ & $21.9 \pm 1.9$ & $22.3 \pm 2.5$ & $22.1 \pm 2.1$ & $21.9 \pm 2.3$ & $22.1 \pm 2.1$ & $21.5 \pm 2.2$ & $21.8 \pm 2.1$ \\
\hline LVFWd (mm) & $4.4 \pm 0.5$ & $4.2 \pm 0.5$ & $4.3 \pm 0.6$ & $4.3 \pm 0.6$ & $4.4 \pm 0.4$ & $4.5 \pm 0.4$ & $4.6 \pm 0.5$ & $4.4 \pm 0.3$ \\
\hline IVSs (mm) & $9.4 \pm 0.7^{\mathrm{a}}$ & $8.6 \pm 0.8^{\mathrm{b}}$ & $8.9 \pm 0.9^{a, b}$ & $8.8 \pm 0.8^{\mathrm{a}, \mathrm{b}}$ & $8.7 \pm 0.9^{b}$ & $9.0 \pm 1.68^{a, b}$ & $8.8 \pm 1^{\mathrm{a}, \mathrm{b}}$ & $8.7 \pm 0.6^{\mathrm{a}, \mathrm{b}}$ \\
\hline LVDs (mm) & $12.0 \pm 1.7^{\mathrm{a}}$ & $13.0 \pm 1.9^{\mathrm{b}}$ & $13.6 \pm 1.6^{\mathrm{b}}$ & $13.3 \pm 1.8^{\mathrm{b}}$ & $13.1 \pm 1.7^{b}$ & $13.1 \pm 1.8^{\mathrm{b}}$ & $13.1 \pm 1.8^{\mathrm{b}}$ & $13.4 \pm 1.8^{\mathrm{b}}$ \\
\hline LVFWs (mm) & $6.7 \pm 1$ & $6.8 \pm 0.5$ & $6.6 \pm 0.7$ & $6.7 \pm 0.8$ & $6.5 \pm 0.7$ & $6.8 \pm 0.8$ & $6.9 \pm 0.8$ & $6.8 \pm 0.9$ \\
\hline $\mathrm{LA}(\mathrm{mm})$ & $22.1 \pm 1.6^{\mathrm{a}}$ & $20.5 \pm 1.6^{\mathrm{b}}$ & $20.9 \pm 1.5^{\mathrm{a}, \mathrm{b}}$ & $20.8 \pm 1.5^{\mathrm{a}, \mathrm{b}}$ & $20.9 \pm 1.6^{\mathrm{a}, \mathrm{b}}$ & $20.9 \pm 1.2^{\mathrm{a}, \mathrm{b}}$ & $20.9 \pm 1.5^{\mathrm{a}, \mathrm{b}}$ & $20.2 \pm 1.7^{b}$ \\
\hline Vcf & $3.1 \pm 0.5^{\mathrm{a}}$ & $3.0 \pm 0.5^{\mathrm{a}, \mathrm{b}}$ & $2.6 \pm 0.6^{\mathrm{b}}$ & $2.8 \pm 0.7^{\mathrm{a}, \mathrm{b}}$ & $2.7 \pm 0.3^{\mathrm{b}}$ & $2.8 \pm 0.4^{\mathrm{a}, \mathrm{b}}$ & $2.7 \pm 0.4^{\mathrm{b}}$ & $2.7 \pm 0.5^{\mathrm{a}, \mathrm{b}}$ \\
\hline RWT & $0.4 \pm 0.05$ & $0.4 \pm 0.04$ & $0.4 \pm 0.06$ & $0.4 \pm 0.06$ & $0.4 \pm 0.06$ & $0.4 \pm 0.05$ & $0.4 \pm 0.06$ & $0.4 \pm 0.07$ \\
\hline
\end{tabular}

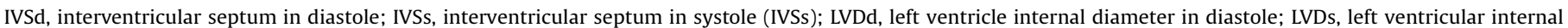

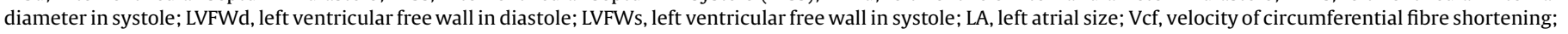
RWT, relative wall thickness. Different superscript letters indicate significant differences $(P<0.05)$ among days. 


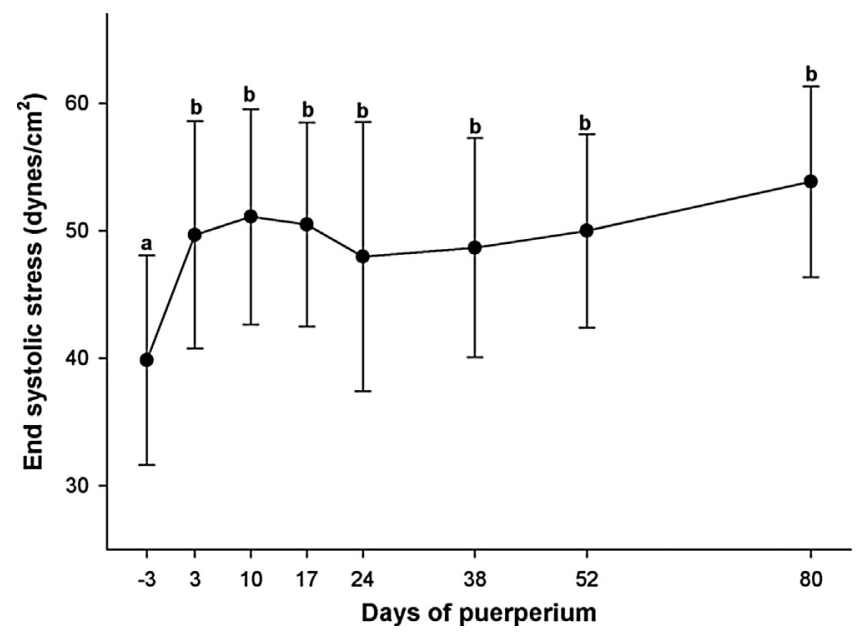

Fig. 2. End systolic stress (ESS; mean \pm standard deviation). Different letters indicate significant differences $(P<0.05)$ among days.

following weeks $(P<0.01$; Fig. 8). Mean electrical axis shifted to the right during this period $(P<0.01$; Table 2$)$. Most of the bitches presented with normal sinus rhythm on day -3 and sinus arrhythmia on day $3(P<0.01)$; all bitches presented with sinus arrhythmia from day 10. P wave duration, PR interval, QRS duration, QT interval and ST amplitude remained unchanged during the study (Table 2). None of the animals presented with pathological arrhythmias during the study.

\section{Discussion}

Consistent with previous reports in human beings (Robson et al., 1987; Pandey et al., 2010) and cattle (Zarifi et al., 2012), we observed a decrease in systolic function and myocardial contractility during the first week after parturition. This finding could be explained by the pronounced decline in preload as a consequence of a reduction in uterine perfusion occurring during the first week after parturition (Batista et al., 2013). Additionally, oxytocin released during parturition and lactation may have a negative inotropic effect (Olsson et al. 2003b). In the rat, oxytocin primarily acts on receptors on parasympathetic postganglionic fibres, stimulating the release of acetylcholine (Mukaddam-Daher et al., 2001), which activates muscarinic receptors in the sinoatrial

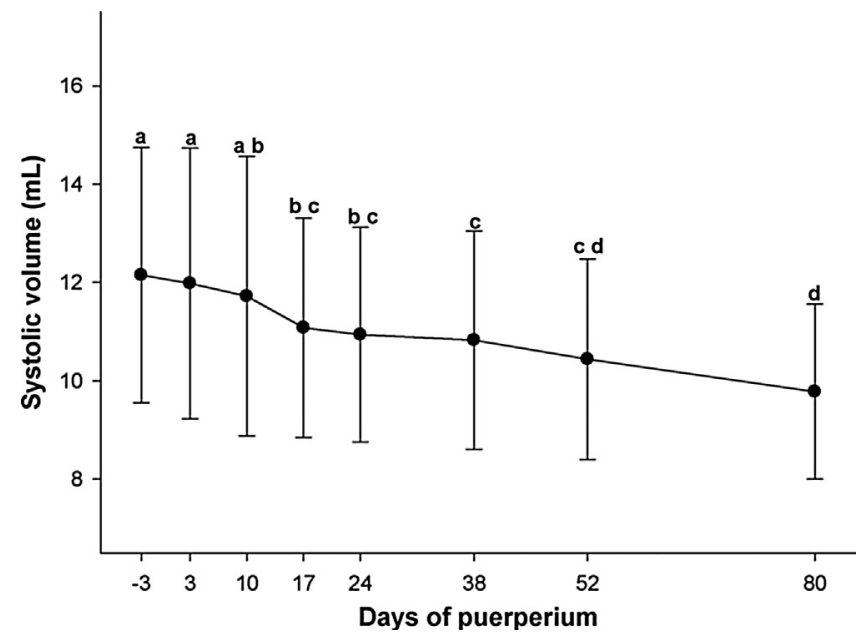

Fig. 3. Systolic blood pressure (SBP; mean \pm standard deviation). Different letters indicate significant differences $(P<0.05)$ among days.

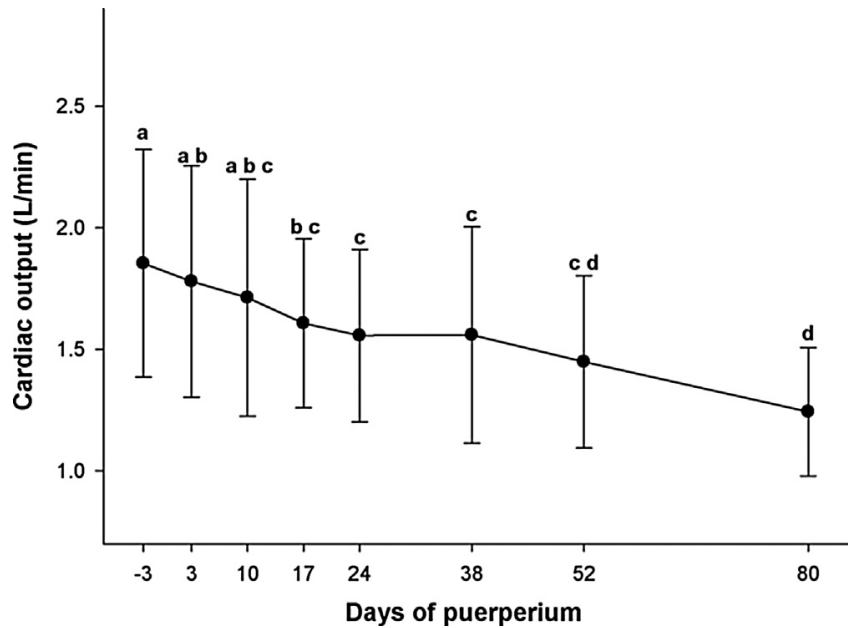

Fig. 4. Systolic volume (SV; mean \pm standard deviation). Different letters indicate significant differences $(P<0.05)$ among days.

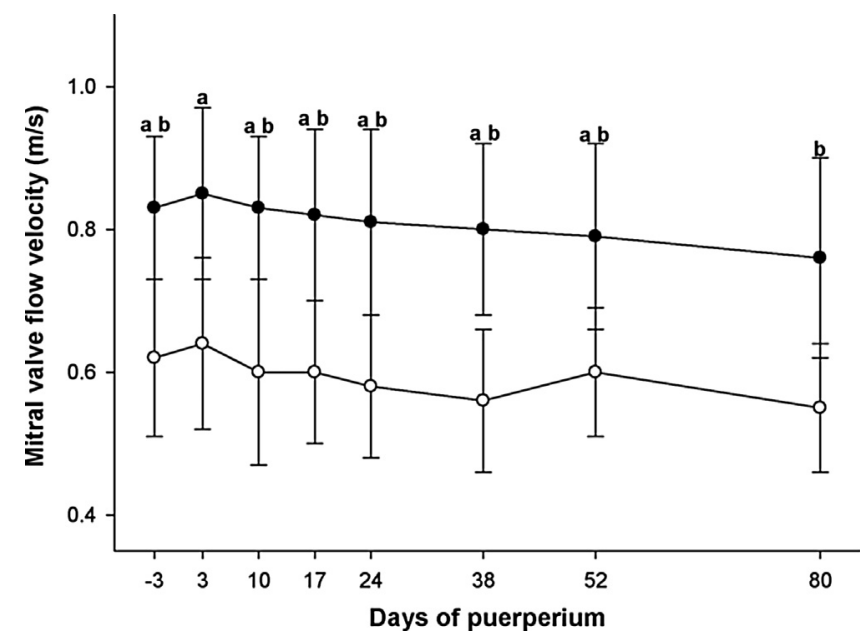

Fig. 5. Cardiac output ( $\mathrm{CO}$; mean \pm standard deviation). Different letters indicate significant differences $(P<0.05)$ among days.

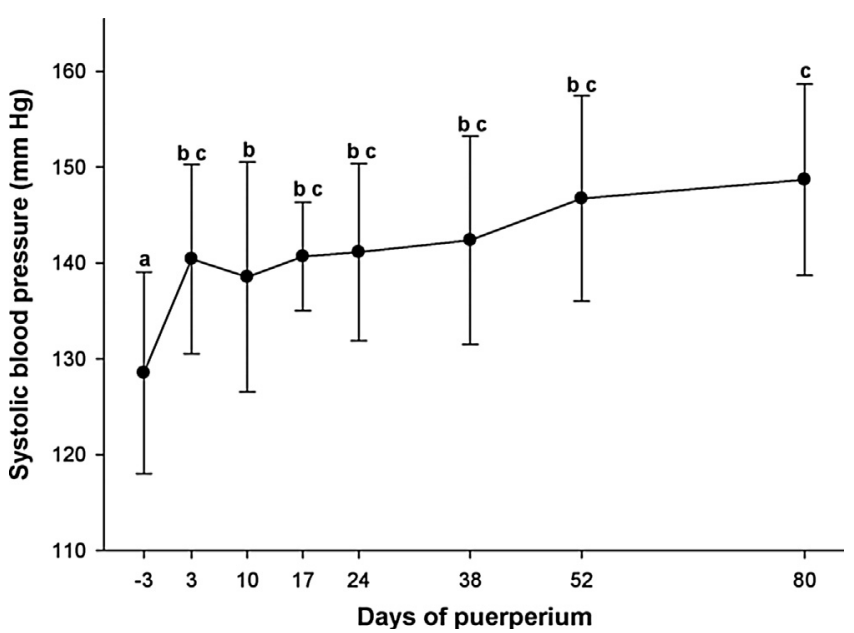

Fig. 6. Mitral E (solid symbols) and A (open symbols) waves ( \pm standard deviation). Different letters indicate significant differences $(P<0.05)$ among days. 


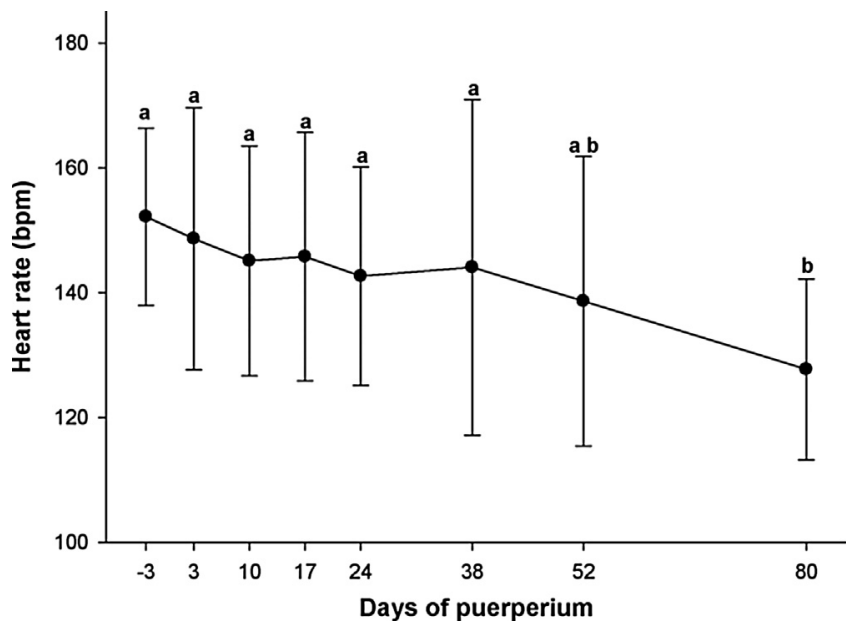

Fig. 7. Heart rate (HR; mean \pm standard deviation). Different letters indicate significant differences $(P<0.05)$ among days.

nodal tissue, resulting in reduced heart rate and contractility (Gutkowska et al., 2014).

The shortening fraction decrease is consistent with previous reports in women and cows (Robson et al., 1987; Zarifi et al., 2012). However, in these species, the variation in shortening fraction is associated with a diminution in left ventricular internal diameter in diastole. In the bitches in our study, this dimension remained unchanged. Instead, the reduced shortening fraction postpartum appears to be caused by an increased left ventricular internal diameter in systole. This result is consistent with a previous study in dogs, in which a decrease in shortening fraction was associated with an increased left ventricular internal diameter in systole after weaning (Abbott, 2010). Similarly, the diminution of uterine perfusion that leads to a reduction in maternal preload may explain the decreases in stroke volume, cardiac output, and E and A wave amplitudes, as well as an increase in systolic blood pressure, in agreement with previous reports in women and cows (Robson et al., 1987; Zarifi et al., 2012). The gradual alterations in these parameters after the first postpartum week can be explained by increased mammary gland perfusion due to the lactational metabolic demand (Mezzacappa et al., 2001; Olsson et al., 2003a).

In women, Schannwell et al. (2002) found that left ventricular wall dimensions returned to normal values 8 weeks after delivery, while Robson et al. (1987) suggested that left ventricular wall hypertrophy of pregnancy is fully resolved 24 weeks after delivery. In our study, gestational cardiac hypertrophy in bitches did not resolve completely during the first 80 days after parturition, suggestive of residual hypertrophy (Blanco et al., 2011). In women, ventricular dimensions and cardiac output appear to be enhanced in subsequent pregnancies (Clapp and Capeless, 1997). Further

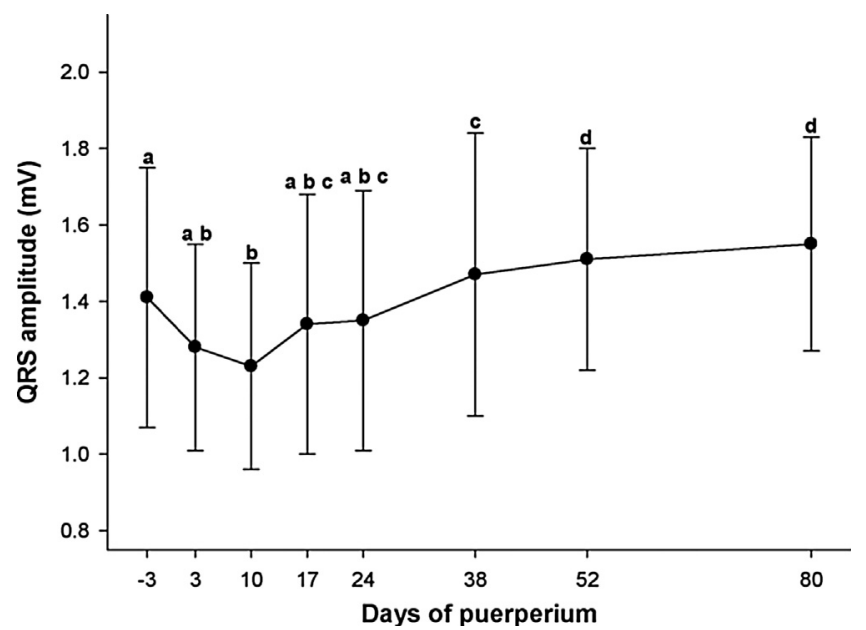

Fig. 8. QRS amplitude (QRSa; mean \pm standard deviation). Different letters indicate significant differences $(P<0.05)$ among days.

studies are needed to confirm if a similar change occurs in consecutive canine gestations.

In our study, heart rate progressively decreased in bitches throughout the postpartum period, consistent with previous findings (Abbott, 2010). The elevated heart rate observed at the end of gestation is related to an increased cardiac output in response to the high metabolic demands of the conceptus (Wong et al., 2002; Blanco et al., 2012). The energy requirements of the bitch remain high during lactation, which might explain the gradual diminution of heart rate throughout the study period (Scantlebury et al., 2000). Respiratory sinus arrhythmia was absent at the end of gestation in most of these bitches. Vagal neural outflow to the sinoatrial node may decrease during this period as observed previously during pregnancy in bitches (Lúcio et al., 2009; Blanco et al., 2012) and women (Baumert et al., 2010). During the postpartum period, increased vagal tone may be responsible for the decreased heart rate and the appearance of respiratory sinus arrhythmia (Tilley, 1992; Mukaddam-Daher et al., 2001).

Changes in P wave and QRS amplitudes in this study were similar to those reported previously in cows (Neubert and Schäfer, 1977; Schäfer and Neubert, 1977). A reduction in P wave amplitude during normal canine gestation may be caused by decreased activity of myocardial potassium channels (Eghbali et al., 2005; Blanco et al., 2011). This alteration may persist during the early postpartum period and appears to revert by day 38 (Pacher et al., 1999).

The abrupt reduction in uterine blood flow after parturition results in a decreased venous return, which could reduce QRS amplitude (Battler et al., 1979). This decrease could also be

Table 2

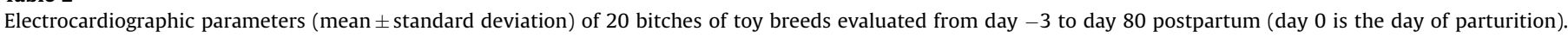

\begin{tabular}{|c|c|c|c|c|c|c|c|c|}
\hline & \multicolumn{8}{|c|}{ Postpartum days } \\
\hline & -3 & 3 & 10 & 17 & 24 & 38 & 52 & 80 \\
\hline MEA (degrees) & $38.6 \pm 13.9^{\mathrm{a}}$ & $48.7 \pm 14.3^{\mathrm{a}, \mathrm{b}}$ & $48.2 \pm 10.1^{\mathrm{b}}$ & $51.7 \pm 17.3^{b}$ & $51.2 \pm 14.9^{\mathrm{b}}$ & $53.1 \pm 15.6^{\mathrm{b}}$ & $52.2 \pm 14.6^{\mathrm{b}}$ & $58.3 \pm 15.4^{\mathrm{b}}$ \\
\hline P wave duration (ms) & $34 \pm 5$ & $34 \pm 4$ & $34 \pm 4$ & $34 \pm 4$ & $33 \pm 4$ & $34 \pm 4$ & $32 \pm 4$ & $34 \pm 3$ \\
\hline P wave amplitude (mV) & $0.21 \pm 0.05^{\mathrm{a}, \mathrm{b}}$ & $0.21 \pm 0.04^{\mathrm{a}}$ & $0.22 \pm 0.04^{\mathrm{a}}$ & $0.23 \pm 0.05^{\mathrm{a}, \mathrm{b}, \mathrm{c}}$ & $0.23 \pm 0.06^{\mathrm{a}, \mathrm{b}, \mathrm{c}}$ & $0.26 \pm 0.06^{\mathrm{b}, \mathrm{c}, \mathrm{d}}$ & $0.29 \pm 0.07^{\mathrm{d}}$ & $0.27 \pm 0.06^{\mathrm{c}, \mathrm{d}}$ \\
\hline PR interval (ms) & $88 \pm 13$ & $90 \pm 14$ & $89 \pm 15$ & $88 \pm 13$ & $89 \pm 14$ & $89 \pm 15$ & $87 \pm 17$ & $87 \pm 15$ \\
\hline QRS (ms) & $47 \pm 5$ & $45 \pm 5$ & $45 \pm 4$ & $45 \pm 5$ & $45 \pm 5$ & $45 \pm 5$ & $45 \pm 5$ & $46 \pm 5$ \\
\hline ST segment (mV) & $-0.10 \pm 0.04$ & $-0.10 \pm 0.04$ & $-0.09 \pm 0.04$ & $-0.10 \pm 0.05$ & $-0.10 \pm 0.05$ & $-0.10 \pm 0.03$ & $-0.10 \pm 0.05$ & $-0.11 \pm 0.04$ \\
\hline QT interval (ms) & $178 \pm 6$ & $178 \pm 10$ & $174 \pm 10$ & $172 \pm 8$ & $173 \pm 9$ & $173 \pm 8$ & $172 \pm 8$ & $176 \pm 10$ \\
\hline QTc (ms) & $231 \pm 7^{\mathrm{a}}$ & $228 \pm 7^{\mathrm{a}, \mathrm{b}}$ & $225 \pm 9^{a, b, c}$ & $223 \pm 7^{b, c}$ & $222 \pm 9^{b, c}$ & $224 \pm 6^{b, c}$ & $220 \pm 9^{c}$ & $0.221 \pm 7^{\mathrm{c}}$ \\
\hline
\end{tabular}

MEA, mean electrical axis; QTc, corrected Q-T interval. Different superscript letters indicate significant differences $(P<0.05)$ among days. 
influenced by an oxytocin-mediated decrease of calcium influx into cardiomyocytes (Mukaddam-Daher et al., 2001; Eghbali et al., 2005).

The QT interval does not change during normal canine gestation (Blanco et al., 2012). Similarly, in the present study, variations of QT interval were not found. Conversely, a progressive decrease in QTc in bitches occurred in the postpartum period. In pregnant mice, myocardial cells develop a reduction in a molecular constituent of the fast transient outward of potassium current, called $\mathrm{I}_{\text {to-f }}$, which is associated with prolonged action potential and therefore a larger QTc (Eghbali et al., 2005). This channel, as well as acetylcholineregulated $\mathrm{K} 1$ channels, are activated by oxytocin, which could explain the decrease in QTc during the postpartum period (Mukaddam-Daher et al., 2001).

The evaluation of cardiovascular variations after parturition provides diagnostic tools to assess the physiological regression of gestational adaptive changes. There would be value in studies comparing lactating and non-lactating bitches postpartum to determine the specific influence of lactation on the regression of gestational cardiac changes. In addition, the present study was limited to toy breeds and therefore the findings cannot necessarily be extrapolated to larger breeds of dogs.

\section{Conclusions}

In toy breeds of dogs, systolic function and some structural adaptive changes of the heart associated with gestation resolved during the first 80 days postpartum. In addition, maternal heart rate and corrected QT interval decreased, while P wave and QRS amplitudes increased.

\section{Conflict of interest statement}

None of the authors of this paper has a financial or personal relationship with other people or organisations that could inappropriately influence or bias the content of the paper.

\section{Acknowledgements}

This study was partially funded by the University Incentive Program of Teaching and ResearchV233 to CG. The authors are Career Scientists (CG and PGB) and Research Fellows (PRB and AA) of the National Research Council (CONICET) of Argentina. Preliminary results were presented as an Abstract at the 2013 American College of Veterinary Internal Medicine (ACVIM) Forum, Seattle, WA, USA, 12-15 June 2013 and at the 25th European College of Veterinary Internal Medicine - Companion Animal (ECVIM-CA) Congress, Lisbon, Portugal, 10-12 September 2015.

\section{References}

Abbott, J.A., 2010. The effect of pregnancy on echocardiographic variables in healthy bitches. Journal of Veterinary Cardiology 12, 123-128.

Batista, P.R., Gobello, C., Corrada, Y., Pons, E., Arias, D.O., Blanco, P.G., 2013. Doppler ultrasonographic assessment of uterine arteries during normal canine puerperium. Animal Reproduction Science 141, 172-176.

Battler, A., Froelicher, V., Slutsky, R., Ashburn, W., 1979. Relationship of QRS amplitude changes during exercise to left ventricular function and volumes and the diagnosis of coronary artery disease. Circulation 5, 1004-1013.

Baumert, M., Seeck, A., Faber, R., Nalivaiko, E., Voss, A., 2010. Longitudinal changes in QT interval variability and rate adaptation in pregnancies with normal and abnormal uterine perfusion. Hypertension Research 33, 555-560.

Blanco, P.G., Batista, P.R., Re, N.E., Mattioli, G.A., Arias, D.O., Gobello, C., 2012. Electrocardiographic changes in normal and abnormal canine pregnancy. Reproduction in Domestic Animals 47, 252-256.

Blanco, P.G., Tórtora, M., Rodríguez, R., Arias, D., Gobello, C., 2011. Ultrasonographic assessment of maternal cardiac function and peripheral circulation during normal gestation in dogs. The Veterinary Journal 190, 154-159.
Boon, J., 1998. The echocardiographic examination. In: Boon, J.A. (Ed.), Manual of Veterinary Echocardiography. Williams and Wilkins, Media, Philadelphia, USA, pp. 35-128.

Brown, S., Atkins, C., Bagley, R., Carr, A., Cowgill, L., Davidson, M., Egner, B., Elliot, J. Henik, R., Labato, M., et al., 2007. Guidelines for the identification, evaluation, and management of systemic hypertension in dogs and cats. Journal of Veterinary Internal Medicine 21, 542-558.

Chetboul, V., Tidholm, A., Nicolle, A., Sampedrano, C.C., Gouni, V., Pouchelon, J.L., Lefebvre, H.P., Concordet, D., 2005. Effects of animal position and number of repeated measurements on selected two-dimensional and M-mode echocardiographic variables in healthy dogs. Journal of the American Veterinary Medical Association 227, 743-747.

Clapp 3rd, J.F., Capeless, E., 1997. Cardiovascular function before, during, and after the first and subsequent pregnancies. American Journal of Cardiology 80, 14691473.

Eghbali, M., Deva, R., Alioua, A., Minosyan, T.Y., Ruan, H., Wang, Y., Toro, L., Stefani, E., 2005. Molecular and functional signature of heart hypertrophy during pregnancy. Circulation Research 96, 1208-1216.

England, G., Yeager, A., Concannon, P.W., 2003. Ultrasound imaging of the reproductive tract of the bitchIn: Concannon, P.W., Verstegen, J., England, G. (Eds.), Recent Advances in Small Animal Reproduction. IVIS, Ithaca, NY USA. . Document A1226.0303 http://www.ivis.org.

Ferasin, L., Ferasin, H., Little, C.J., 2010. Lack of correlation between canine heart rate and body size in veterinary clinical practice. Journal of Small Animal Practice 51, 412-418.

Gottdiener, J.S., Bednarz, J., Devereux, R., Gardin, J., Klein, A., Manning, W.J., Morehead, A., Kitzman, D., Oh, J., Quinones, M., et al., 2004. American Society of Echocardiography recommendations for use of echocardiography in clinical trials. Journal of the American Society of Echocardiography 17, 1086-1119.

Gutkowska, J., Jankowski, M., Antunes-Rodrigues, J., 2014. The role of oxytocin in cardiovascular regulation. Brazilian Journal of Medical and Biological Research 47, 206-214.

Kienle, R.D., 1998. Echocardiography. In: Kittelson, M.D., Kienle, R.D. (Eds.), Small Animal Cardiovascular Medicine. Mosby, St. Louis, USA, pp. 95-117.

Lúcio, C.F., Silva, L.C., Rodrigues, J.A., Veiga, G.A., Vannucchi, C.I., 2009. Peripartum haemodynamic status of bitches with normal birth or dystocia. Reproduction in Domestic Animals 44, 133-136.

Mezzacappa, E.S., Kelsey, R.M., Myers, M.M., Katkin, E.S., 2001. Breast-feeding and maternal cardiovascular function. Pyschophysiology 38, 988-997.

Mukaddam-Daher, S., Yin, Y.L., Roy, J., Gutkowska, J., Cardinal, R., 2001. Negative inotropic and chronotropic effects of oxytocin. Hypertension 38, 292-296.

Nagueh, S.F., Appleton, C.P., Gillebert, T.C., Marino, P.N., Oh, J.K., Smiseth, O.A., Waggoner, A.D., Flachskampf, F.A., Pellikka, P.A., Evangelista, A., 2009. Recommendations for the evaluation of left ventricular diastolic function by echocardiography. Journal of the American Society of Echocardiography 22, 107-133.

Neubert, C., Schäfer, M., 1977. Untersuchungen zum EKG frischlaktierender Kühe. 1. Mitteilung: Das EKG in den ersten wochen der laktation und bei eiweibüberangebot in der ration. Archiv fur Experimentelle Veterinarmedizin 31, 575-580.

Olsson, K., Hansson, A., Hydbring, E., von Walter, L.W., Häggstrom, J., 2001. A serial study of heart function during pregnancy, lactation and the dry period in dairy goats using echocardiography. Experimental Physiology 86, 93-99.

Olsson, K., Lagerstedt, A.S., Bergström, A., Häggström, J., 2003a. Change of diurnal heart rate patterns during pregnancy and lactation in dogs (Canis familiaris). Acta Veterinaria Scandinavica 44, 105-110.

Olsson, K., Bergström, A., Kindahl, H., Lagerstedt, A.S., 2003b. Increased plasma concentrations of vasopressin, oxytocin, cortisol and the prostaglandin F2 $\alpha$ metabolite during labour in the dog. Acta Physiologica Scandinavica 179, $281-$ 287.

Pacher, P., Ungvári, Z., Nánási, P.P., Mucha, I., Kecskeméti, V., Losonczy, G., 1999. Postpartum prolongation of the atrial repolarization in rabbit. Acta Physiologica Scandinavica $16,1-5$.

Pandey, A.K., Banerjee, A.K., Das, A., Bhawani, G., Kumar, A., Majumadar, B., Bhattacharya, A.K., 2010. Evaluation of maternal myocardial performance during normal pregnancy and post partum. Indian Heart Journal 62, 64-67.

Poole, A.T., Vincent, K.L., Olson, G.L., Patrikeev, I., Saade, G.R., Stuebe, A., Bytautiene, E., 2014. Effect of lactation on maternal postpartum cardiac function and adiposity: a murine model. American Journal of Obstetrics and Gynecology 211 (424), e1-7.

Rishniw, M., Erb, H.N., 2000. Evaluation of four 2-dimensional echocardiographic methods of assessing left atrial size in dogs. Journal of Veterinary Internal Medicine 14, 429-435.

Robson, S.C., Hunter, S., Moore, M., Dunlop, W., 1987. Haemodynamic changes during the puerperium: a Doppler and M-mode echocardiographic study. British Journal of Obstetrics and Gynaecology 94, 1028-1039.

Scantlebury, M., Butterwick, R., Speakman, J.R., 2000. Energetics of lactation in domestic dog (Canis familiaris) breeds of two sizes. Comparative Biochemistry and Physiology Part A: Molecular and Integrative Physiology 125, 197-210.

Schäfer, M., Neubert, C., 1977. Untersuchungen zum EKG frischlaktierender Kühe. 2. Das EKG im vergleich zum verhalten einiger parameter des mineralstoff - und kohlenhydrat - fettstoffwechsels. Archiv fur Experimentelle Veterinarmedizin 31, 581-589.

Schannwell, C.M., Zimmermann, T., Schneppenheim, M., Plehn, G., Marx, R., Strauer, B.E., 2002. Left ventricular hypertrophy and diastolic dysfunction in healthy pregnant women. Cardiology 97, 73-78. 
Tattersall, M.L., Dymond, M., Hammond, T., Valentin, J.P., 2006. Correction of QT values to allow for increases in heart rate in conscious Beagle dogs in toxicology assessment. Journal of Pharmacological and Toxicological Methods 53, 11-19.

Thomas, W.P., Gaber, C.E., Jacobs, G.J., Kaplan, P.M., Lombard, C.W., Moise, N.S., Moses, B.L., 1993. Recommendations for standards in transthoracic twodimensional echocardiography in the dog and cat. Echocardiography Committee of the Specialty of Cardiology, American College of Veterinary Internal Medicine. Journal of Veterinary Internal Medicine 7, 247-252.

Tilley, L.P. (Ed.), 1992. Essentials of Canine and Feline Electrocardiography. Lippincott Williams \& Wilkins, Pennsylvania, PA, USA pp. 40-50, 127-207.
Vuille, C., Weyman, A.E., 1994. Left ventricle I: general considerations, assessment of chamber size and function. In: Weyman, A.E. (Ed.), Principles and Practice of Echocardiography. Williams \& Wilkins, Philadelphia, PA, USA, pp. 575-624.

Wong, A.Y., Kulandavelu, S., Whiteley, K.J., Qu, D., Langille, B.L., Adamson, S.L., 2002 Maternal cardiovascular changes during pregnancy and postpartum in mice. American Journal of Physiology. Heart and Circulatory Physiology 282, 918-925.

Zarifi, M., Buczinski, S., Rezakhani, A., Mokhber Dezfouli, M.R., Khonsha, A., 2012. Effect of lactation on functional and morphological echocardiographic variables in adult dairy cows. Journal of Veterinary Cardiology 14, 415-421.

Zatuchni, J., 1951. The electrocardiogram in pregnancy and puerperium. American Heart Journal 42, 11-17. 